\title{
CUANDO AMAR EN ÁFRICA LO PAGAS CON LA VIDA
}

\author{
When loving in Africa costs you your life
}

Elena García-Oliveros*

\begin{abstract}
Resumen. El caso real de Marianna, lesbiana de origen senegalés, demandante de asilo en la ciudad de Bruselas, Bélgica, es la clave de este artículo que gira en torno a los modelos de persecución específicos de las mujeres homosexuales y las causas de su invisibilidad. El estudio se detiene específicamente en la mutilación genital femenina infligida con el agravante de lesbofobia y en el análisis de la simbología patriarcal que esta práctica conlleva y que conduce a su perpetuación hoy en día. Igualmente se exploran los datos acerca de la falta de sistematización en la denuncia de esta forma de proceder como modo de control del lesbianismo y las consecuencias que esta impunidad conllevan sobre las mujeres que huyen de sus países de origen buscando refugio. La investigación se enmarca dentro del proyecto de Arte Comunitario Cuando Amar en África lo pagas con la vida (2011) creado por Toxic Lesbian.
\end{abstract}

Palabras clave: lesbiana; asilo; mutilación genital femenina; migraciones; arte comunitario.

Abstract. The true case of Marianna, a lesbian from Senegal requesting asylum in Brussels, Belgium, is the key of this article that revolves around styles of persecution specifically of homosexual women and the reasons for their invisibility. The study deals specifically with female genital mutilation inflicted in aggravation of lesbo-phobia and in the analysis of the patriarchal symbolism that this practice entails and which leads to its perpetuation even today. An exploration is also done of the data about lack of systemization in reporting this practice as a means of control of lesbianism and the consequences this impunity has on women who must flee from their countries of origin seeking refuge. The investigation is part of the project of Community Art titled When loving in Africa costs you your life (2011) created by Toxic Lesbian.

Keywords: lesbian; asylum; female genital mutilations; migrations; Community Art.

* Universidad Complutense de Madrid. Madrid, España. E-mail: elena.free@gmail.com. Orcid: 0000-0003-1515-1058. 


\section{Introducción}

Esta propuesta ahonda, en el marco del proyecto artístico Cuando Amar en África lo pagas con la vida ${ }^{1}$, en uno de los casos participantes en esta propuesta de Arte Comunitario. Dirigido por la autora de este artículo bajo el pseudónimo de Toxic Lesbian² entre los años 2010 a 2012, fue producido en el contexto de la residencia de artista en El Ranchito, Centro de Creación artística Matadero, Madrid, España (figura 1).

Figura 1 - Toxic Lesbian, Cuando amar en África lo pagas con la vida, 2011. Sesiones Vj durante conciertos en Matadero, Madrid

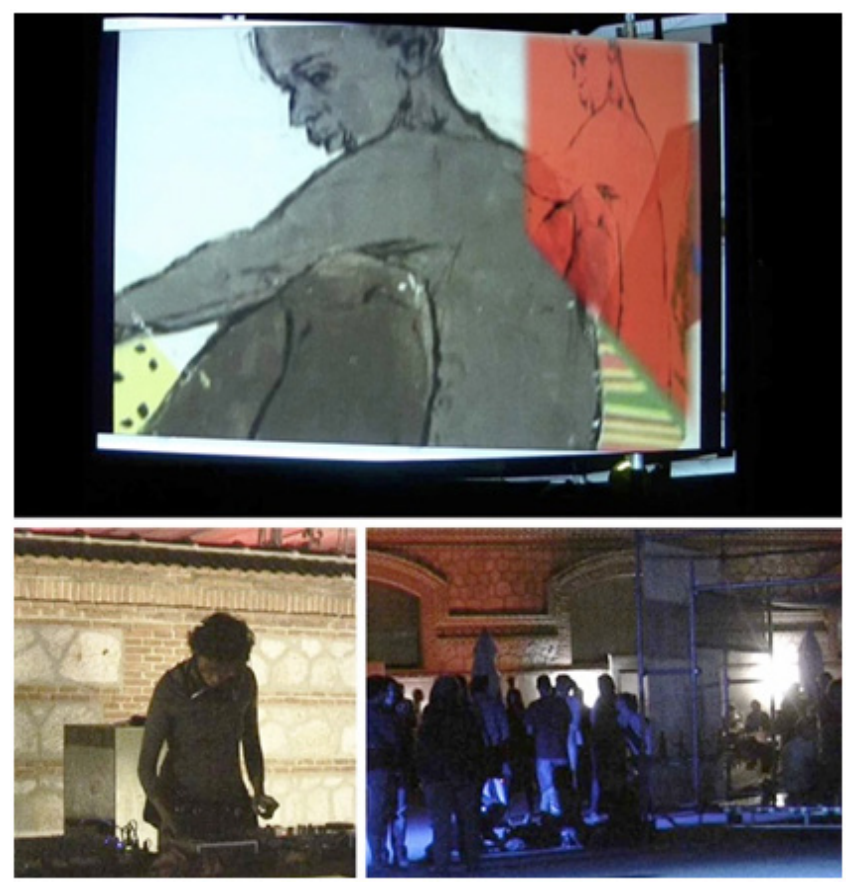

Fuente: $<$ https://bit.ly/2YM2Flv>

La metodología de la investigación desarrollada fue cualitativa, sustentada en entrevistas personales a las protagonistas, informadoras privilegiadas de los hechos expuestos, reconstruyendo así sus historias de vida con la participación de diversas organizaciones aquí citadas. Se articuló desde

1 El proyecto está disponible en su conjunto en <https://www.toxiclesbian.org/proyectos-de-artepublico-y-ciberfeminismo/amar-en-africa/>.

2 Toxic Lesbian (www.toxiclesbian.org) da nombre a los proyectos de Arte Comunitario desarrollados desde perspectiva de género y orientación sexual, en colaboración con instituciones públicas y colectivos sociales, desde licencias copyleft, digitales y difundidos en la red. 
principios de investigación-acción en la medida en que implica a la propia comunidad afectada con quien la autora de este artículo compartió los procesos de creación de Cuando Amar en África lo pagas con la vida. Cabe señalar que su doble papel como investigadora y artista visual, generó una conexión directa con las fuentes. En el marco del Arte Comunitario en el que se inscribe, sus objetivos persiguen la generación de narrativas de creación audiovisual y performance contextualizadas para centros de arte y sus públicos. La comunidad concernida, detallada para este caso en el siguiente párrafo, es el primer círculo de colaboración con la producción de las piezas creadas en la medida en que ofrece sus testimonios verbales y visuales como material de base de la producción artística. En consecuencia, estas obras procesuales muestran otra perspectiva para la experiencia estética abordada desde la reflexión y la denuncia, conectándose así con la tradición del arte político y activista. Fiel a los postulados de la investigación-acción, Cuando Amar en África lo pagas con la vida pretende la transformación de los hechos que denuncia con el apoyo del compromiso de los múltiples agentes que intervienen en su consecución. De modo más específico, el estudio trata de demostrar la falta de especificidad en el acercamiento a la realidad de las lesbianas y en este caso de las procedentes de África e inmersas en procesos de asilo. Igualmente, el cómo el trato recibido, desde la realidad que atañe a los hombres gays que les es ajena, perjudica como demostraremos sus procesos e invisibiliza sus casuísticas personales. Ahondaremos en las consecuencias que esta forma de proceder implica y que son concretadas a continuación.

Mujeres subsaharianas, lesbianas o no, algunas demandantes de asilo, otras migrantes o con nacionalidad europea, mujeres que aman a otras mujeres en países africanos (figura 2), donde amar se paga con la vida, con la ablación o la violación; organizaciones mediadoras con estos colectivos, a nivel europeo o nacional; mujeres artistas, queer, feministas y negras, creadoras desde su condición, fueron los agentes ${ }^{3}$ buscados por Toxic Lesbian para crear con formato público y procesual Cuando Amar en África lo pagas con la vida (figura 3). Esta investigación de modo específico se centra en una de las fuentes del proyecto: el testimonio de Marianna recabado en Bruselas, Bélgica, en febrero de 2011 de la mano de la organización belga LGTBQ $^{4}$

3 El marco de esta obra de Arte Comunitario se desarrolla en Madrid -España-, París -Franciay Bruselas -Bélgica-. Contó con la colaboración de organizaciones generalistas de derechos humanos como Amnistía Internacional -Bélgica-, QueerAmnesty -Suiza-, de refugiados y migrantes como Merhaba -Bélgica- o CEAR -España-, específicas de género como Women's Link Worldwide -España- o propiamente LGTBQ como ILGA World -Bélgica-, RQTR -Españae instituciones como la Universidad Complutense madrileña o el Centro de Creación Contemporánea Matadero, Madrid, así como artistas como la fotógrafa queer sudafricana Zanele Muholi o el grupo de arte urbano Keller de La Tabacalera, Madrid.

4 El orden de las siglas LGTB o LGBT así como la inclusión de la Q -queer- varía para cada organización 
Merhaba $^{5}$, quien apoyaba su proceso de demanda de asilo en Europa por su orientación sexual. En las entrevistas realizadas, Marianna explica cómo le fue practicada la escisión como medio de 'curación' de su lesbianismo y cómo tuvo que huir de su país, Senegal, por la persecución sufrida en 2010. La entrevista fue llevada a cabo por Toxic Lesbian en el contexto del proyecto realizado en esta ciudad. A partir de la descripción del trato que recibió al postularse como demandante de asilo, ahondaremos en la descripción de la persecución a mujeres queer tanto en sus países de origen africanos como en otros, en su sentido simbólico respecto a ciertas claves de construcción del heteropatriarcado ${ }^{6}$ y en sus conexiones desde la perspectiva interseccional con el racismo institucional.

\section{Figura 2 - Toxic Lesbian, Cuando amar en África lo pagas con la vida, 2011. Videocreación en colaboración con lesbianas demandantes de asilo de países africanos}

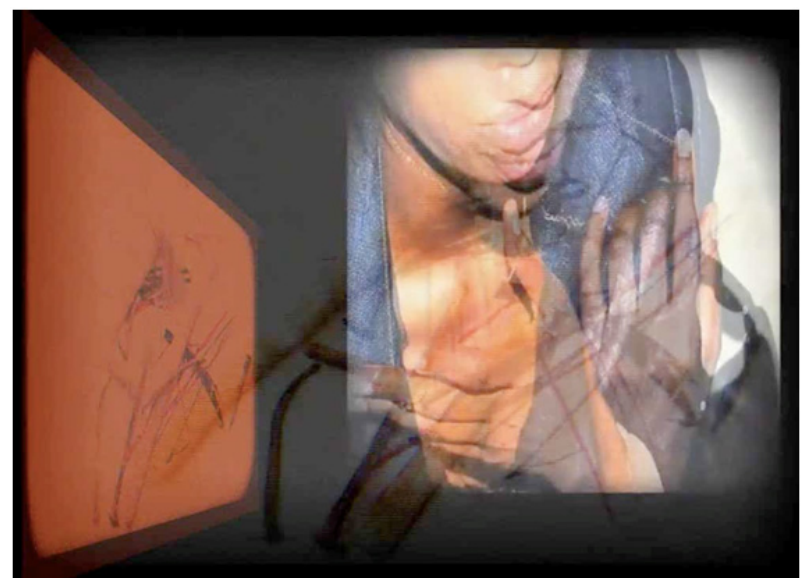

Fuente: <https:/bit.ly/3dcQHq9>.

en función del criterio de prioridades que quieran otorgar a unos u otros colectivos representados por cada sigla. En este artículo se mantiene el modo con el que cada organización se identifica.

5 Merhaba, organización belga para la defensa de las personas LGTBQ de origen mahgrebí, africano o árabe en general.

6 El patriarcado entendido como el dominio del criterio del hombre frente al de la mujer subordinada tanto en el espacio privado como en el público y donde se hacen prevalecer los valores tradicionales instituidos desde estas prácticas consolidadas a lo largo de la historia. Analizado desde la perspectiva de Curiel (2013) quien expone la tesis de que la heterosexualidad, más allá de una orientación sexual, es un sistema político, en línea con las lecturas pioneras de esta perspectiva de Witting y Rich. Esta afirmación la sostienen las autoras esbozando de qué modo la idea de Nación se ampara en instituciones como la familia, la maternidad, la pareja heterosexual, el derecho masculino y patriarcal, la representación de los hombres con privilegios sobre el resto, el patrimonio y la filiación. Continúan explicando consecuentemente que la idea universal de hombre y mujer en dependencia uno del otro, definidos desde la producción y la reproducción, necesitarían al heteropatriarcado para mantener su Statu quo. 
En consecuencia, el interés de esta investigación radica en la obtención de estos testimonios de las protagonistas de los hechos, en la contextualización de las fuentes relacionadas con organizaciones colaboradoras o respuestas aportadas por las instituciones para el tratamiento de estos casos, lo que nos permite un marco de análisis desde el aparato crítico del lesbofeminismo interseccional elegido para este estudio. Veremos, desde este punto de vista, en dónde radican las circunstancias que llevan a la constante negación e invisibilización de hechos como los que aquí se narran o a la desconexión con el relato de los modelos de persecución de las lesbianas.

Figura 3 - Toxic Lesbian, Cuando amar en África lo pagas con la vida, 2011. Carátula de presentación del proyecto

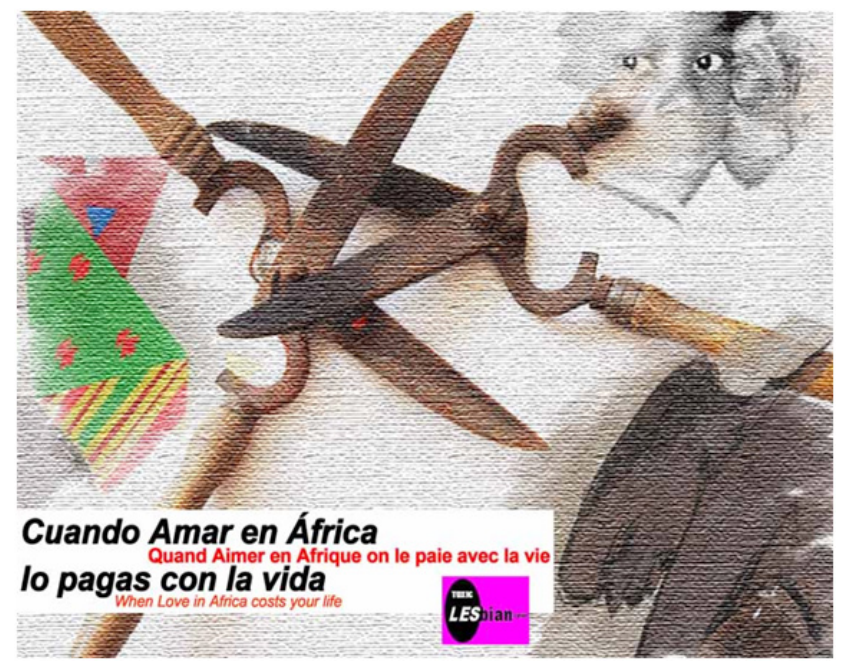

Fuente: $<$ https://bit.ly/2CaKcqR $>$.

\section{El castigo patriarcal al lesbianismo y su invisibilidad}

Durante varias décadas, el incipiente movimiento LGBT, apoyado en sus orígenes por los fondos económicos para la lucha contra el SIDA y muy centrado en las problemáticas de los hombres gays, afirmaba que las lesbianas no eran perseguidas o discriminadas por su orientación como sí lo eran los varones homosexuales (Gimeno, 1999). Este prejuicio se mantiene incluso en la actualidad y explica, entre otros factores, conductas reflejadas en este estudio. La construcción de la lesbiana (figura 4) como la 'otredad' la explica Ochy Curiel (2013) en tanto "sujetas", como refiere la autora, antítesis del hombre heterosexual, a lo que cabría añadir su no blanquitud que refuerza la idea de 'otra' al margen de lo que debe ser en el caso de las lesbianas racializadas, 
objeto de este análisis. Este 'ser otra' aísla y oscurece sistemáticamente las realidades contadas desde este paradigma, como veremos.

\section{Figura 4 - Toxic Lesbian, Cuando amar en África lo pagas con la vida, 2011. Videocreación}

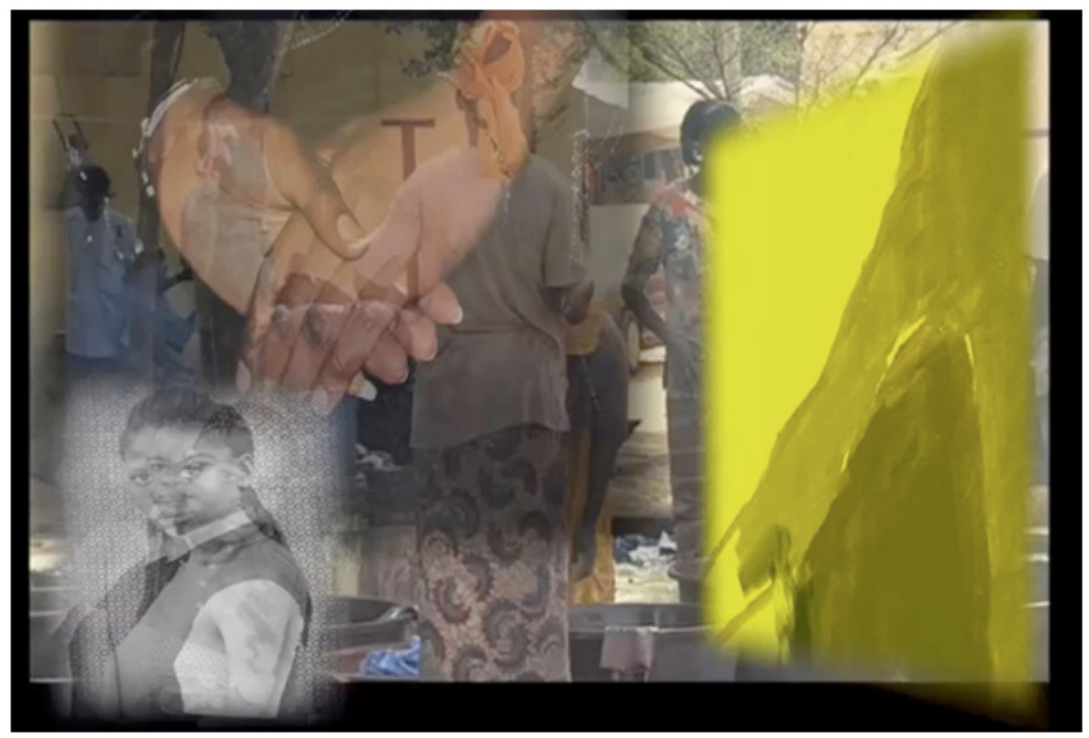

Fuente: <https://bit.ly/37H1kAh>.

Gloria Anzaldúa y Cherríe Moraga (1981) realizan uno de los primeros análisis interseccionales ${ }^{7}$ incidiendo en las subjetividades contadas desde la raza. Con esta perspectiva afirmamos cómo las lesbianas no blancas condensan esta imagen de la 'otredad' desde la mirada de los países europeos, como es el caso que nos ocupa.

El análisis interseccional desembocará en la tercera ola del feminismo en los años 90 donde florecerá este concepto. La obra de Moraga gira precisamente en torno a las experiencias de las mujeres lesbianas de minorías

\footnotetext{
La interseccionalidad es un enfoque que subraya que el género, la etnia, la clase o la orientación sexual, como otras categorías sociales, lejos de ser 'naturales' o 'biológicas', son construidas y están interrelacionadas. Es el estudio de las identidades sociales solapadas o intersectadas y sus respectivos sistemas de opresión, dominación o discriminación. La teoría sugiere y examina cómo varias categorías biológicas, sociales y culturales como el género, la etnia, la clase, la especie, la discapacidad, la orientación sexual, la religión, la casta, la edad, la nacionalidad y otros ejes de la identidad interaccionan en múltiples y a menudo simultáneos niveles. La teoría propone que debemos pensar en cada elemento o rasgo de una persona como unido de manera inextricable con todos los demás elementos, para poder comprender de forma completa la propia identidad. Este marco puede usarse para comprender cómo ocurre la injusticia sistemática y la desigualdad social desde una base multidimensional.
} 
raciales en Estados Unidos, sobre todo las latinas, mientras que la de Anzaldúa se establece esencialmente en la idea de mezcla de culturas y también de idiomas. Introduce en el panorama estadounidense el concepto de mestizaje y acuña la denominación de la 'nueva mestiza' refiriéndose a un sujeto que se sabe en sus conflictos de identidad incorporando desde esta consciencia un nuevo punto de vista que desafía al pensamiento blanco. La situación que creará nuestro caso de análisis es una versión performativa de este desafío por cuanto irrumpe en las estructuras de reivindicación de derechos, -demanda de asilo ante la Corte belga-, con una identidad claramente subalternizada desde la perspectiva del patriarcado como sería la de una lesbiana racializada y migrante en Europa.

La negación de la persecución de las lesbianas en sus países de origen con las especificidades que les son propias, así como su exilio y posterior solicitud de asilo a países terceros, con características diferentes de las de sus compañeros gays o trans, y que ya tuvimos ocasión de estudiar en artículos anteriores (García-Oliveros, 2018), forzó al Alto Comisionado de las Naciones Unidas para los Refugiados a publicar en 2014 un documento en el que denuncia estos hechos. Con ello pretendía esta institución evitar que desconozcan las casuísticas que rodean al colectivo las administraciones que deben dar acogida a estas refugiadas, o incluso los propios magistrados encargados de sus procesos de asilo. O del mismo modo, que tomen decisiones claramente erradas con dictámenes como los publicados en esos años, donde se obvia la diversidad de estas apelantes. No será el único éste de Naciones Unidas: otros textos legales vendrán a apoyar la visibilización de las circunstancias que acontecen a las lesbianas para procurarles un mayor amparo en sus solicitudes.

Las motivaciones de esta negación de las violaciones de los derechos de las lesbianas hay que buscarlas originariamente en la propia estructura patriarcal necesariamente heterosexual, como explica, entre otras, Monique Witting (1978). Esta estructura subyace también en la justicia. Para la autora, el contrato social de Rousseau es intrínsecamente heterosexual en la medida en que implica normas y cumplimiento de convenciones que además están sostenidos por un vínculo social: el hecho de vivir juntos. Las lesbianas quedarían al margen de este contrato simbólico y de los beneficios de su convivencia pactada, hito en la construcción de las sociedades contemporáneas. Del mismo modo, Adrienne Rich (1980) abunda en la idea de que la heterosexualidad obligatoria perjudica a las lesbianas al ser una naturaleza que 'necesita ser explicada'. Su sola existencia contradice la versión de una mujer recorrida por la concepción, natalidad y crianza de los hijos. Rich insiste, al igual que Witting, en que la heterosexualidad sea estudiada en tanto institución política y aclara cómo lo lesbiano únicamente podría ser tolerado en ese marco en algunos casos. Uno, en tanto fenómeno de la clase privilegiada siendo considerado una decadencia de esta élite, 
-expone en este sentido los casos de lesbianas parisinas de salón como Renée Vivien o Natalie Clifford Barney-. Otro, en aquellas parejas de lesbianas que son consideradas como una versión 'anormal' de la heterosexualidad, es decir, cuando en el marco de su relación encarnan papeles heterosexuales y una de sus componentes es identificada con la cultura masculina. Por consiguiente, y leído desde planteamientos lesbofeministas, esta rígida estructura política heterosexual, hermética al hecho lesbiano, deforma y reprime cada una de nuestras instituciones y sin una explícita deconstrucción cualquier agente es víctima de ella. En los ejemplos citados a continuación podremos dar cuenta de ello.

En 2011, fecha en la que se realizó Cuando Amar en África lo pagas con la vida y se tomaron los testimonios que aquí se analizan, Naciones Unidas, en una campaña explícita por los derechos LGBT, difunde el cómo empezó este debate en 1994 a raíz del caso Toonen contra el gobierno australiano. En la mención a los modelos de persecución homofóbicos no hace referencia a aquellos propios de las lesbianas, sino que se refiere exclusivamente a los crímenes cometidos contra la población gay y por añadidura que pudieran también serlo eventualmente contra las lesbianas. Este ejemplo nos muestra que el hecho de luchar contra la discriminación homofóbica no implica un reconocimiento del cómo se realiza. Las campañas son genéricas y hablan de términos como 'discriminación', 'humillación', 'agresión', 'violencia ejercida contra', entre otra terminología similar que no precisa de qué modo la sociedad quebranta de manera explícita los derechos LGBT para cada uno de los grupos sociales que lo conforman. Esta indefinición propicia que las víctimas continúen siéndolo hoy en día ya que los agentes encargados de su protección en primera línea no pueden identificar los delitos cometidos desde el agravante de la persecución homofóbica, sino simplemente como lesiones, daños o acoso contra las personas en general. No olvidemos que la pérdida de esta perspectiva LGBTfóbica implica el rechazo de su demanda de asilo.

El texto publicado en 2014 por Naciones Unidas pretende luchar contra la invisibilización de la persecución lesbiana describiendo detalladamente qué es esta identidad. En ese epígrafe del documento expone de qué modo son sometidas a represalias por parte de sus excompañeros y esposos o igualmente son obligadas a contraer matrimonio al declararse su orientación sexual, sufriendo reiteradas violaciones dentro de esta unión -recordemos que la violencia sexual entre los cónyuges no ha sido reconocida como un delito hasta muy recientemente ${ }^{8}$-. Este texto de ACNUR de carácter muy pedagógico,

8 Hasta 1993 el Alto Comisionado de Naciones Unidas para los Derechos Humanos no estableció que la violación marital era una violación contra los derechos humanos, siendo anteriormente considerado como un derecho de los cónyuges el disfrute de las relaciones sexuales, consentidas o no, dentro del matrimonio. La asunción como delito en los códigos penales de cada país varía a lo largo de siglo XX pero en muchos de ellos no ha sido establecido como tal. 
desmitifica el hecho de que las lesbianas vivan su identidad en todo momento, explicando que han podido tener relaciones heterosexuales con bastante frecuencia e incluso casarse y tener hijos, sin por ello perder su orientación sexual genuina, y habiendo por el contrario optado por estos otros caminos debido a la presión social ejercida sobre ellas.

Por otra parte, ACNUR hace igualmente referencia a los hechos que los casos que recogimos en 2011, tres años antes de la aparición de esta campaña que ahora nos sirve de muestra, mencionan, y al modo en que las demandas de asilo son valoradas por los jueces de modo estereotipado y con total desconocimiento de las formas de vida de las mujeres homosexuales. Como ya describíamos en nuestro artículo de 2018, estas solicitudes de asilo son denegadas por no poder probar su lesbianismo, analizado éste desde los mismos parámetros de la homosexualidad en los hombres. De hecho, el texto de ACNUR señala que las solicitudes de refugio de los gays no deben ser tomadas como un modelo de consulta para otros casos relacionados con la orientación sexual. Esta insistencia se debe al reconocimiento implícito de la multitud de denuncias de discriminación en sus procesos presentadas por lesbianas, pero también de transexuales y transgénero. Este fue precisamente el caso discriminatorio que Marianna sufrió durante su demanda de asilo (GarcíaOliveros, 2018) y que le llevó a apelar hasta tres veces hasta obtener finalmente su condición de refugiada.

Por otra parte, y respecto a la concreción de las formas de persecución que atañen a las mujeres lesbianas, en el mismo epígrafe del documento de ACNUR que estamos analizando, se reconoce explícitamente que sufren habitualmente daños por agentes no estatales, describiendo uno de los actos más activamente ocultados durante largas décadas en la narración de la persecución de las lesbianas: la denominada 'violación correctiva'. En el proyecto (figura 5) Cuando Amar en África lo pagas con la vida se abordan precisamente casos en este sentido que son detallados en nuestra investigación de 2018.

Este reconocimiento de que la violación es una forma de castigo por la orientación sexual no fue tampoco otorgado socialmente desde los inicios de la construcción de los derechos y garantías LGBT, como es de suponer. Se trató, de hecho, de un tipo de persecución demostrado hacia los hombres gays y que afectaría por añadidura a las lesbianas. Los casos que ACNUR expondrá para llegar a la consideración de que la violación es una forma de intimidación, degradación, humillación o castigo debido a la orientación sexual y por tanto debe ser tenida en cuenta en las solicitudes de asilo, se refieren a procesos abiertos y reconocidos a hombres gays -Aydin contra Turquía, 1996; el fiscal contra Jean Paul Akayesu, Tribunal Penal Internacional para Ruanda 2001; fiscal contra Anto Furundzja, 1998 Tribunal Penal Internacional para la ex Yugoslavia; entre otros-. Es decir, ni siquiera el proceso de reconocimiento 
como persecución homofóbica de esta casuística, -la violación-, tan ad-hoc para las lesbianas en tanto mujeres, ha tomado en consideración sus casos para definirlo. Por el contrario, será incorporado desde la realidad de los hombres homosexuales a todo el colectivo LGBT en general. Es frecuente, en los procesos reivindicativos de los derechos de las personas homosexuales dentro de las instituciones, partir de la realidad masculina estrictamente.

Figura 5 - Toxic Lesbian, Cuando amar en África lo pagas con la vida, 2011. Diálogos abiertos con diversos agentes inmersos en el proyecto en el Centro de Creación Contemporánea Matadero, Madrid, España. Octubre, 2011

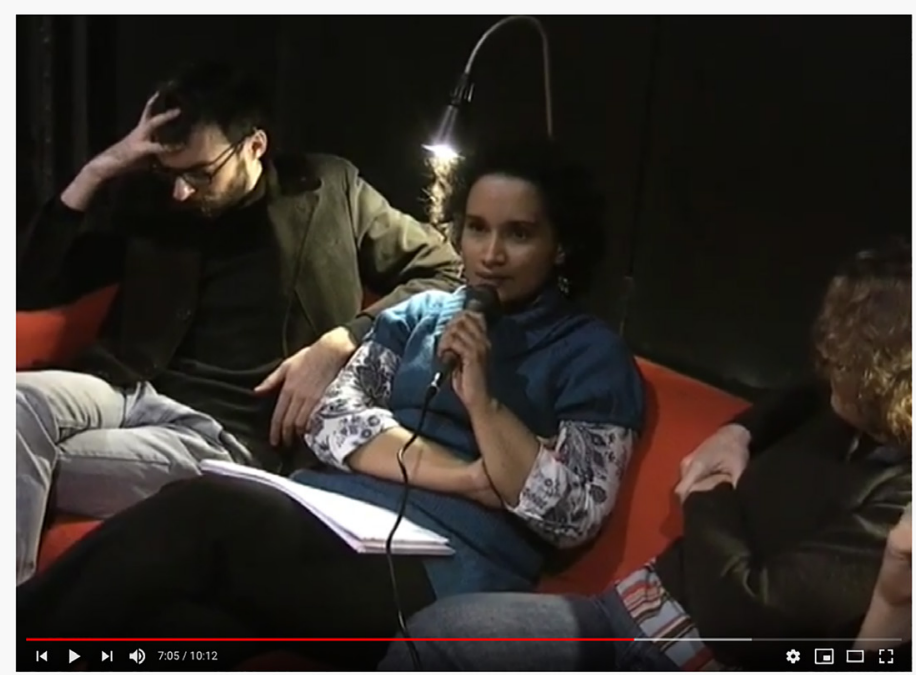

Dialogos Abiertos 21 octubre 2011, Matadero, Madrid, PARTE IV

Fuente: <https://bit.ly/3hxSZDL>

Sin embargo, y a pesar de todo ello, es interesante destacar que este citado documento es explícito acerca de la violencia ejercida dentro de las familias por el hecho de ser lesbianas, reconociendo que corren éstas un especial riesgo en este entorno junto con las personas bisexuales y transgénero. Esta evidencia abre al fin el camino para comprender dónde se producen gran parte de las discriminaciones hacia las lesbianas: en el medio más cercano y doméstico. Del mismo modo, da una explicación acerca de porqué se han negado sistemáticamente al ser considerada tradicionalmente la violencia dentro de las familias un 'asunto privado'. Además, el texto detalla, intentando desmontarla, la falsa creencia muy extendida de que se podría evitar su persecución si estas mujeres fuesen discretas. Diversas sentencias así lo han argumentado para rechazar demandas de asilo y defender que si procedieran 
de esta manera no sería necesario reconocerles este derecho. ACNUR prosigue precisando que las lesbianas se ven amenazadas de ser descubiertas contra su voluntad por rumores, accidente o creciente sospecha por no cumplir con los comportamientos esperados como casarse y tener hijos. Este dato se vincula con la construcción de la 'otredad lesbiana' que trata Rich (1980) y que hemos mencionado anteriormente. Finalmente, el documento es concluyente al reconocer los daños psicológicos al igual que los físicos.

A pesar de todo, este texto, si bien lucha contra esta invisibilización permanente del hecho lésbico insistiendo en las particularidades que atañen a estas identidades, no hace mención a una forma de persecución propia exclusivamente de las mujeres homosexuales y que es la que el caso de Marianna viene a ilustrarnos: el de la mutilación genital femenina desde el agravante de ser producida por su orientación sexual, es decir, por causa homofóbica. Lo estudiamos a continuación desde la protagonista de los hechos.

\section{La ablación del clítoris como persecución lesbofóbica: Marianna, un caso real}

El testimonio voluntario de Marianna (figura 6) que oculta sus rasgos a la cámara pero no su nombre, ni su voz, ni la expresión de sus manos, explica de qué modo le es practicada la escisión del clítoris pasada su infancia y su primera adolescencia, periodo en el que habitualmente en su país de origen, Senegal, suele llevarse a cabo esta agresión contra el cuerpo de la mujer. En aquel momento inicial, nos aclara, su familia decidió no realizársela. Por el contrario, y al conocer su orientación sexual, sí.

La mutilación genital femenina es una práctica ancestral, como explica Bedía (2017) que se produce todavía en la actualidad a pesar de las múltiples campañas de información donde se explican las consecuencias sobre la salud de la mujer tales como riesgo vital, hemorragia, shock, complicaciones tardías infecciosas agudas, así como consecuencias psicológicas y psiquiátricas ya definidas por estudios científicos. Consiste en la resección total o parcial de los genitales externos femeninos mediante técnicas cruentas y en extremo dolorosas -la costumbre no dispone medida antiálgica ninguna- en circunstancias normalmente de falta de higiene y prevención de infecciones añadidas a la mutilación. En ocasiones va del mismo modo acompañada del estrechamiento de la abertura vaginal mediante la sutura, o incluso de perforaciones, incisiones, raspado o cauterización de la zona. Es decir, se trata de un modelo de tortura de extraordinaria crueldad dada la sensibilidad y gran número de capilares de la zona añadido a la corta edad de las víctimas de estas prácticas. Un rito de estas características, como podemos imaginar, tiene un significado simbólico de gran poder, además de una justificación inconsciente, para el grupo social que lo inflige. Apoyándose en ello, los 
familiares y responsables de la comunidad neutralizarían la lógica censura que podría evitar perpetrar la mutilación.

Figura 6 - Toxic Lesbian, Cuando amar en África lo pagas con la vida, 2011. Imagen del testimonio recogido de Marianna

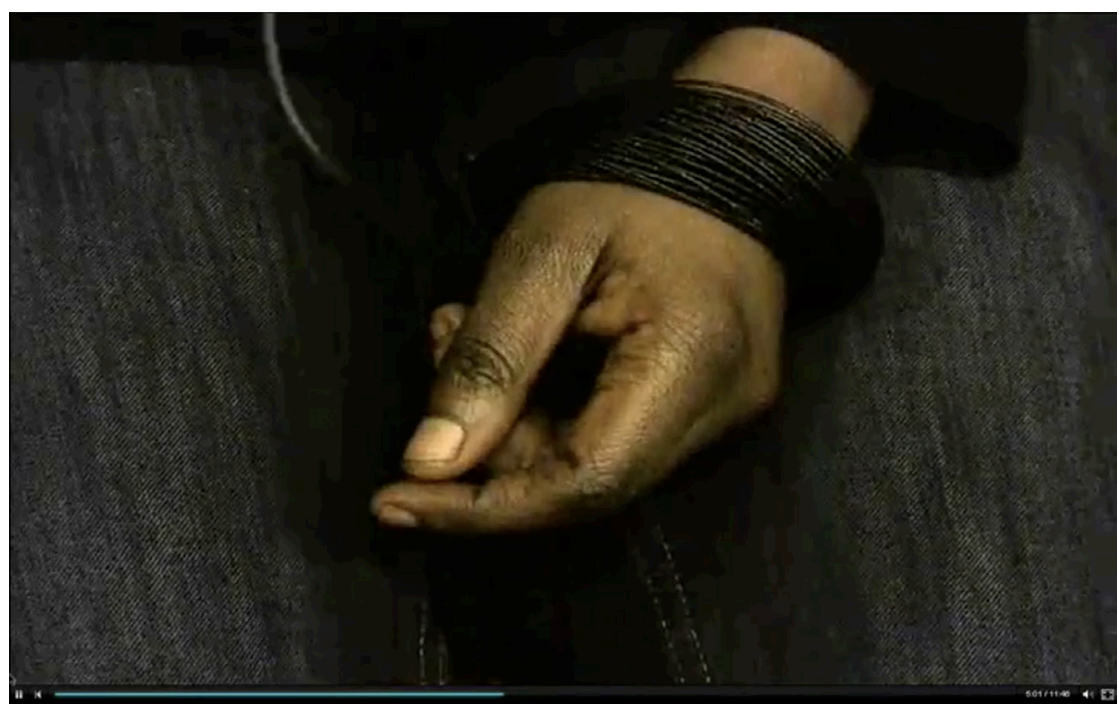

Fuente: < https://bit.ly/3ecHeAf > .

Manu Mediavilla (2016), relator para Amnistía Internacional, explica que la mutilación genital femenina es concebida como un rito de iniciación por parte de quienes lo practican y en algunos pueblos africanos además se considera que el clítoris es un atributo masculino, por lo que para que una mujer alcance la femineidad absoluta es preciso privarla de estos rasgos masculinizantes y así poder considerarla pura. En América Latina, prosigue, se ejecuta para impedir que las mujeres se conviertan en "marimachas" o lesbianas. Es decir, vemos en uno u otro caso que la relación con las máximas del patriarcado como sistema de jerarquización del poder es evidente. La ablación se configura como un medio de control de la subalternidad que debe prevalecer en las mujeres, una llave para mantenerlas en un segundo plano impidiendo el propio placer, recordándoles incluso, con la amputación del clítoris, que nada debe sobresalir en ellas como emulación del pene. Adrienne Rich ya menciona en 1980 la clitoridectomía ${ }^{9}$ como ejercicio del poder de los hombres para negarles su sexualidad y en su caso, penalizar la sexualidad lesbiana. En segundo lugar, hace referencia al uso de la violación como otra muestra con el mismo objetivo. Describe las

9 Ablación del clítoris o mutilación genital femenina. 
condiciones a las que las mujeres han sido sometidas por los hombres para garantizarse el acceso sexual y entre las cuales hace constar la mutilación genital femenina, citando diversas fuentes de estudio. A este estado Rich lo denomina la heterosexualidad obligatoria, describiendo estos mecanismos de imposición que implicarían igualmente la invisibilidad de la opción lesbiana. Precisamente en su relato, Marianna hace mención a estas mismas categorías simbólicas como presentes en la decisión de perpetrar finalmente en ella la ablación: es su abuela, como fuente de la tradición, quien denuncia que es necesaria la escisión para eliminar sus conductas desviadas, enfermas, para por fin someter su voluntad a la del hombre. Sus padres, explica, no pueden argumentar nada frente al peso de la costumbre y al de estas poderosísimas imágenes heredadas que configuran el inconsciente colectivo de las comunidades. De este modo claudican y aceptan la ablación de su hija de 17 años. Incluso después de haber sido torturada y huir de su país, Marianna se siente víctima de la exclusión, del rechazo familiar y cree que nunca podrá ser aceptada, como nos declara.

La historia de vida de Marianna conecta con el texto de Kate Millet (1969) en el que describe cómo la integración de los valores del patriarcado por parte de la gran mayoría se produce con tal docilidad que la violencia no es necesaria. A pesar de ello, prosigue la autora, sí necesitan estos valores del apoyo de la fuerza para consolidar su hegemonía: se trataría entonces de lanzar señales de intimidación constantes para mantener sus normas firmes y bajo estricto cumplimiento. Podemos imaginar sin mucho esfuerzo a partir de este marco que nos dibuja con claridad Millet, de qué modo la necesidad de ocultar una identidad lesbiana aparece en sociedades donde la tortura, no ya simbólica, sino explícita, es ejercida contra esta orientación sexual.

A pesar de la crudeza de estos testimonios y la evidente relación con el agravante lesbofóbico en el ejercicio de esta agresión, las organizaciones de mujeres y LGBT continúan sin asociar la ablación a la discriminación por orientación sexual en lesbianas. El relato de las víctimas una y otra vez permanece opaco, incapaz de provocar, a pesar de su gravedad, el amparo de la denuncia internacional. Marianna tuvo que recurrir, como hemos mencionado, hasta tres veces su demanda de asilo ya que no se consideraba "suficientemente probado" que se tratase de "una verdadera lesbiana" y que las cicatrices, reales e innegables, de su escisión podrían no haber sido producidas por su condición de homosexual. Podemos citar como ejemplo de esta indiferencia institucional a Amnistía Internacional (1998) que en diversos informes exhaustivos publicados en torno a la ablación no menciona en ningún momento entre las causas de la misma el control de la homosexualidad femenina, mientras que sí explica (Mediavilla, 2016) las motivaciones relacionadas con el control del placer sexual de las mujeres, la virginidad prematrimonial o la fidelidad. Nuevamente parece que las lesbianas no existen en el marco de un relato heterosexualizado. 
Cabe destacar por otra parte y como último dato relevante en lo que se refiere al interés de la comunidad concernida por este tema, el elevado seguimiento que este caso ha tenido en las redes sociales de Toxic Lesbian desde su publicación en 2011 en YouTube. Se trata del vídeo con mayor número de visionados de este proyecto artístico que recaba en sus dos canales casi un total de 500 recursos audiovisuales desde 2007. Es especialmente interesante el análisis temporal y geográfico de las visitas al testimonio de Marianna (figuras 7 y 8). En el primer cuadro vemos que en un solo día se reciben más de 11.000 visitas. Esto es lo que denominamos un fenómeno viral. En un total de tres días en esas mismas fechas, marzo de 2011, al poco tiempo de haberse realizado la subida del vídeo, se alcanzan las 20.000 para posteriormente caer, pero a pesar de ello alcanzar las casi 90.000 visualizaciones. Esto significa para una pieza de temática marginal desde la perspectiva del Statu quo, como es en definitiva aquella que concierne a mujeres, racializadas y lesbianas, un número muy elevado de pases. Más notorio si estudiamos desde dónde se realizan estos visionados de la entrevista. Como podemos apreciar en la figura 8, el epicentro del fenómeno viral es Senegal, el país de origen de Marianna. En esos tres días 20.000 personas en este país africano con acceso a Internet visualizan el vídeo de nuestra colaboradora. Podemos afirmar que en ese breve periodo de tiempo el relato de Marianna se convirtió en un tema recurrente de conversación. Si nos fijamos en los datos del segundo cuadro, de los casi 90.000 pases, la mitad proceden de Senegal. Es decir, el vídeo ha continuado siendo visto en esta localización. Dado que no tenemos más datos por recabar, sólo podemos aventurarnos a lanzar hipótesis acerca del interés despertado por la pieza. ¿Estamos ante espectadores de la comunidad LGTB? Es improbable por el enorme número de pases que haya sido promovido por una comunidad muy estigmatizada, sin poder e invisible, sin acceso prácticamente a los centros de activismo como sería la lésbica en Senegal. En consecuencia, podemos pensar que es la sociedad general quien se ha interesado por estos contenidos. En este caso, ¿qué ha promovido su interés? Podría ser el desafío fehaciente de las normas que el testimonio de Marianna simboliza: a pesar de la ablación estamos ante una mujer que escapa a este control y solicita la protección europea. O también frente a la osadía por quebrantar los rigores del patriarcado, con un reconocimiento explícito de su valor, por tanto. No cabe duda que a pesar de la muy probable indignación que sus palabras hayan podido suscitar, la viralización es un claro reconocimiento a su triunfo sobre estas prácticas. 
Figura 7 - Captura de pantalla de los resultados del vídeo de Toxic Lesbian, Entretien avec Marianna, lesbienne demandeuse d'asyle 2011. Recoge el detalle de la temporalidad

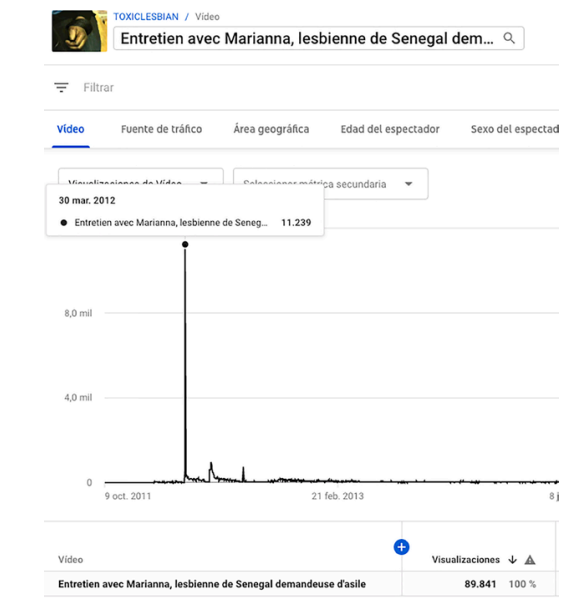

Fuente: @toxiclesbian, YouTube, Analytics
Figura 8 - Esta segunda captura de los analytics del mismo vídeo muestran la distribución geográfica de los visionados totales obtenidos

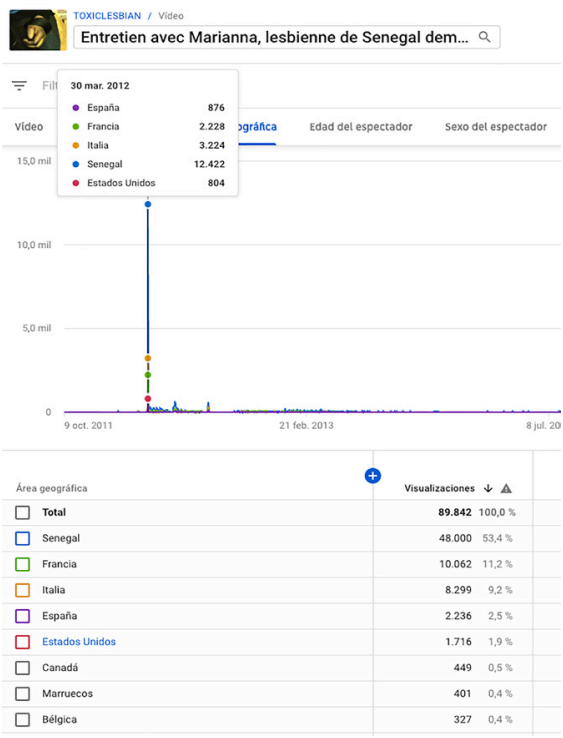

Fuente: @toxiclesbian, YouTube, Analytics

\section{Conclusiones}

El caso de Marianna nos abre la puerta hacia el debate acerca de la invisibilidad de los modelos concretos de persecución del lesbianismo. Como hemos visto, la generalización en la descripción de las conductas por la experiencia vital de los hombres gays ha supuesto un grave perjuicio discriminatorio para las lesbianas en sus procesos de demanda de asilo. Igualmente, la falta de investigación de casos de mujeres ha provocado una reiterada ausencia de informes de agentes protectores de los derechos humanos respecto a la casuística que a ellas les concierne. Tengamos en cuenta que son los informes de estas organizaciones reconocidas las que sirven a los tribunales para argumentar sus sentencias en este contexto. Puntualmente algunas instituciones han procurado rellenar estos vacíos, pero sólo de modo parcial, sin realmente profundizar en la diversidad lésbica. Este hecho hemos podido probarlo con el caso de Marianna y la opacidad en torno al tema de la mutilación genital femenina como forma de tortura con el agravante de 
persecución homofóbica. Si bien para las autoras lesbofeministas que hemos citado, la ablación del clítoris está claramente connotada con el control del placer de la mujer y el castigo del lesbianismo, este planteamiento no ha estado en el punto de mira del relato heteropatriarcal, no ya de las instituciones jurídicas y sociales europeas en el caso que nos ocupa, sino de las propias organizaciones que deberían asegurar la igualdad de derechos.

Del mismo modo, hemos relacionado estos hechos con significados más profundos analizados desde la perspectiva de autoras lesbofeministas. Conectando a partir de ellas las causas que producirían semejante apagón sistémico obtendríamos una explicación a las interrogantes planteadas. Entendido como un sistema político, como una organización para el poder que ni siquiera requiere del uso de la violencia para que sus normas sean acatadas, la heterosexualidad es ese perfecto contexto donde la voz de las mujeres disidentes, en cuyo extremo estarían las lesbianas, no puede sino ser ignorada.

El análisis interseccional, no en vano articulado en sus inicios por autoras lesbianas racializadas, nos ofrece el resto de claves para comprender, en el periodo de tiempo del caso de este estudio, la nula concesión de asilo a lesbianas en Europa procedentes de territorios africanos. Las trazas de lo que se evidencia como racismo institucional parecen aflorar a medida que vamos profundizando en el relato de estos hechos.

Ha pasado casi una década desde el testimonio de Marianna y la realidad se ha movido únicamente de un modo sutil, apenas sin inmutarse por los dramas que subyacen a esta falta de visión. Estas estructuras endémicamente contagiadas de modos de pensar centenarios parece que precisan de la denuncia reiterada y sin tregua para evitar que se instalen en esta misma nada: nada de escucha, nada de apoyo, nada de consuelo. Solo con las inestimables salvedades de pequeñas organizaciones muy comprometidas en el terreno como las que hemos citado.

\section{Referencias bibliográficas}

ACNUR. La protección internacional de las personas LGBTI. Mexico: ACNUR, 2014. Disponible en: <https://www.acnur.org/fileadmin/Documentos/Publica ciones/2014/9872.pdf > . Acceso el: 12.12.2019.

ANZALDÚA, Gloria; MORAGA, Cherry. This bridge called my back. Writings by radical women of color. Massachusetts: Persephone Press, 1981.

BEDÍA Fidel; SALAMANCA, Rocío. Reflexión bioética, criminológica y tratamiento jurídico penal de la mutilación genital femenina. Bioética. 2017. Disponible en: $<$ https://www.bioeticaweb.com/reflexion-bioetica-criminologica-y-tratamientojuridico-penal-de-la-mutilacion-genital-femenina/> . Acceso el: 12.12.2019.

CURIEL, Ochy. La Nación Heterosexual. Bogotá: Brecha Lésbica y en la Frontera, 2013. 
GARCÍA-OLIVEROS, Elena. Exilio Queer, invisibilidad de género y arte público. Arte y Políticas de Identidad, v. 18, p. 33-54, 2018. Disponible en: <https:// revistas.um.es/reapi/article/view/335991>. Acceso el: 12.10.2018.

GIMENO, Beatriz. La marginación de las lesbianas en los grupos gays y en el movimiento feminista. 1999. Disponible en: <https://beatrizgimeno. es/1999/08/14/la-marginacion-de-las-lesbianas-en-los-grupos-gays-y-en-elmov-feminista/> . Acceso el: 04.01.2020

La mutilación genital femenina y los derechos humanos. Amnistía Internacional, 1998. Disponible en: <http://www.corteidh.or.cr/tablas/12056.pdf>. Acceso el: 03.01.2020.

MARIANNA [@toxiclesbian]. Entrevista con Marianna, lesbiana demandante de asilo de Senegal [Archivo de vídeo], 2011. Disponible en: <https://www. youtube.com $/$ watch $? \mathrm{v}=\mathrm{nwycBwDiByM} \&$ index $=9$ \&list $=\mathrm{PL} 3101 \mathrm{C} 84 \mathrm{E} 0 \mathrm{~F} 895 \mathrm{~F}$ 9E>. Acceso el:10.06.2014.

MEDIAVILLA, Manu. Mutilación genital femenina, a golpe de "dolor, sangre y gritos". Amnistía Internacional, 2016. Disponible en: < https://www.es.amnesty. org/en-que-estamos/blog/historia/articulo/mutilacion-genital-femenina-a-golpede-dolor-sangre-y-gritos/>. Acceso el: 20.12.2019.

MILLET, Kate. Política Sexual. Madrid: Ed. Cátedra, 1969.

$\mathrm{RICH}$, Adrienne. La heterosexualidad obligatoria y la existencia lesbiana. Journal of Women in Culture and Society, v. 5, n. 4, University Chicago Press, 1980.

UN Human Rigths [@toxiclesbian]. Como comenzó el debate de los derechos humanos de las personas LGBT en Naciones Unidas [Archivo de vídeo]. 2011. Disponible en: <https://www.youtube.com/watch?v=9nrgvGoJdZo\&index =19 \&list $=$ PL3101C84E0F895F9E $>$. Acceso el: 13.05.2014.

TOXIC LESBIAN [@toxiclesbian]. Proyecto arte público, Cuando amar en África lo pagas con la vida [Archivo de vídeo], 2011. Disponible en: < http://toxiclesbian. org/amar-en-africa/>. Acceso el: 15.05.2014.

WITTING, Monique. The straigth mind, 1978. In: La pensée straight. Paris: Ed. Balland, 2001. 